\title{
Identidad y rivalidad entre Real Madrid y FC Barcelona en el léxico de las crónicas futbolísticas del diario Marca
}

\section{Resumen:}

El presente artículo analiza la expresión léxico-semántica de la identidad y rivalidad de Real Madrid y FC Barcelona en las crónicas deportivas del diario Marca. A partir del análisis estadístico de tipos léxicos y concordancias en un corpus textual, caracterizamos los términos relativos al concepto 'equipo', en relación con ambos clubes. Analizamos el léxico que identifica y caracteriza a ambos clubes, así como la forma en la que estas palabras designan por medio de la denotación, identificación y connotación en las crónicas analizadas.

Palabras clave: lenguaje periodístico, fútbol, léxico, designación, terminología, identidad
Abstract:
Identity and Rivalry between Real Madrid and FC Barcelona in the Lexicon of the Football Chronicles of the Newspaper Marca
This article analyzes the lexical and semantic expression of the identity and ri- valry of Real Madrid and FC Barcelona in the sports chronicles of the news- paper Marca. Based on the statistical analysis of word types and concordances in a textual corpus, the terms relating to the concept of 'team', regarding both clubs, were charcterized. Two things were analyzed: the lexicon that identifies and characterizes both clubs and the way in which these words are designated by means of denotation, identification and connotation in the analyzed chronicles. 
Keywords: journalistic language, football, lexicon, designation, terminology, identity

\section{La crónica deportiva de fútbol}

El género periodístico dominador de la prensa deportiva española es, sin duda alguna, la crónica deportiva de fútbol. Las crónicas deportivas, completadas con marcadores, datos estadísticos y declaraciones, constituyen el grueso de la información deportiva al término de los partidos de cada jornada de competición futbolística (Rojas Torrijos, 2012: 90).

La dimensión temporal está íntimamente ligada al género de la crónica periodística. El mismo término crónica deriva de la voz griega "cronos", que significa 'tiempo'. En la crónica "estamos ante relatos en [los] que se observa una sucesión temporal de acontecimientos, con un hilo conductor", en el que se refiere "lo sucedido entre un periodo delimitado” de tiempo (Marín Montín, 2000: 243), es decir, la crónica "hace referencia a una narración ligada a la secuencia temporal" (Yanes Mesa, 2006). Además, las crónicas deportivas se escriben de manera rápida y se publican inmediatamente al acabar el evento noticioso. Finalmente, la crónica se caracteriza por su regularidad, lo "que da lugar a que un mismo autor, un mismo tema o un mismo espacio de referencia se repitan con frecuencia” (Moreno Espinosa, 2000: 177).

La crónica se define como la "narración directa e inmediata de una noticia con ciertos elementos valorativos, que siempre son secundarios respecto a la narración del hecho en sí” (Martínez Albertos, 1983: 361). En el caso del fútbol, la crónica sintetiza y analiza el partido de fútbol de un modo cronológico, explicando los lances del juego y valorando la actuación individual de los jugadores, entrenadores o de los equipos contrincantes. Esto hace de la crónica un género controvertido por su carácter híbrido, al mezclar continuamente la información de los hechos reales y noticiables con la interpretación y el comentario que de ellos hace el cronista (Moreno Espinosa, 2000: 176). Actualmente, las crónicas deportivas "se caracterizan por ser subjetivas, atractivas y muy visuales, haciendo hincapié en las fotografías, en la 
ficha técnica y en las infografías que acompañan al texto", al tiempo que "los cronistas, reflejan su propia personalidad en las crónicas deportivas” (Romero Pérez, 2015: 188).

Moreno Espinosa (2000: 175-176) destaca tres rasgos de las crónicas:

a) La limitación del suceso en el tiempo y en el espacio. Aquí se restringiría a la duración del partido y a lo ocurrido en el terreno del juego.

b) La necesidad de testimoniar el relato con la presencia in situ del informador. Las crónicas futbolísticas son escritas por los periodistas que asisten al partido y hacen el seguimiento del equipo, jugadores y cuerpo técnico.

c) La inclusión de juicios valorativos procedentes del cronista en la propia narración de los acontecimientos. Estas valoraciones van de la loa a la crítica.

En cuanto a su estructura, "la crónica deportiva está compuesta de ficha técnica (a menudo independiente del texto), titulación, entrada, desarrollo y cierre" (Álvarez Pedrosa, 2017: 69). La ficha técnica del fútbol incluye puntuaciones de los protagonistas del encuentro, así como datos relativos a los lances del juego: goles, faltas, amonestaciones, cambios, etc.

\section{Identidad, identificación y rivalidad en lenguaje futbolístico}

Como apunta Medina Montero (2007: 197), “el lenguaje del fútbol se incluye en las denominadas lenguas especiales, esto es, subsistemas de la lengua común o estándar referidos sobre todo al léxico, por medio de los que se identifica un determinado ámbito sociocultural". Así, el lenguaje del fútbol pertenece a los lenguajes sectoriales, pues presenta un componente sociológico marcado por ciertas actividades y ámbitos profesionales, y puede servir como forma de identificación entre los miembros del grupo que integra la comunidad discursiva del fútbol. Entre sus miembros se incluyen grupos de personas como los futbolistas, los entrenadores, los aficionados, y los periodistas. 
Según Naranjo de Arcos (2011: 203), “los grupos enfrentados en el ámbito del deporte (o fútbol, en este caso) lo son a partir de cierto nivel de identificación", ambos con la actividad deportiva compartida, expresada con un léxico característico, y cada grupo con la emoción que en el fútbol "ayuda a identificarse con determinados personajes (deportista) o colectivos (equipo)”, y que es experimentada conjuntamente durante las competiciones por deportistas y afición. Cuando existe rivalidad deportiva, la identidad deportiva está influida por una "lógica segmentaria de identificación-oposición" (Augé, 1999: 56). Es decir, los miembros de cada grupo se identifican no solo por los rasgos propios de su grupo, sino también por la oposición con el rival, en el que "la desgracia de unos es la condición para la alegría de otros" (Bromberger, 1999: 34 apud Naranjo de Arcos, 2011: 203).

En el fútbol español, la máxima rivalidad y protagonismo la acaparan dos clubes: Real Madrid y FC Barcelona. Ambos equipos representan a las dos principales ciudades españolas, con una rivalidad que trasciende lo meramente deportivo para entrar en el terreno social, político, ideológico, identitario y económico. Cada equipo ha cultivado filosofías y estilos de juego distintos a partir de grandes jugadores y entrenadores en su historia: el Real Madrid aparece ligado, entre otros, a sus éxitos en la máxima competición europea en la época de las 5 copas de Europa de Alfredo Di Stefano (1955-1960), a la figura de su presidente Santiago Bernabeu (1943-1978), que da nombre a su estadio, o al equipo de Cristiano Ronaldo que ganó 4 ligas de campeones entre 2013 y 2018. El FC Barcelona, por su parte, es denominado en catalán mes que un club con una identificación catalanista, asociándose su juego al estilo de control y toque de entrenadores como Johan Cruyff (1988-1996) y Pep Guardiola (20072012), a la escuela de fútbol de La Masía, y al equipo de Lionel Messi que ganó 8 ligas nacionales entre 2008 y 2019 y tres ligas de campeones entre 2008 y 2015.

\section{Objetivos y metodología}

El objetivo de este trabajo es analizar el léxico que identifica en las crónicas deportivas a los máximos rivales del fútbol español: Real 
Madrid y FC Barcelona, así como explorar si la identidad de ambos clubes necesita de la rivalidad entre ellos. Ponemos el foco en las denominaciones nominales -sustantivos y adjetivos- que aluden a estas entidades deportivas. Indagamos en la expresión léxica de los conceptos que aluden a ambos equipos, y en su modo de significar, en tanto que equipos de fútbol y entidades deportivas. Analizamos las unidades léxicas que designan la interrelación equipo-club, en los mecanismos de denotación, identificación y connotación. El fin último es analizar qué imagen y valoración se proyecta sobre estos conceptos en función del equipo protagonista de la crónica deportiva.

Para el análisis léxico tomamos al azar 18 crónicas de partidos de la liga de fútbol, del Real Madrid y del FC Barcelona, publicadas en la página web del diario Marca, entre las temporadas 2009/2010 y 2017/2018. Corresponden al periodo en el que a la rivalidad entre los dos equipos se sumó la rivalidad entre sus dos futbolistas estrella, Cristiano Ronaldo y Lionel Messi. Analizamos dos crónicas por temporada, una por cada vuelta (ronda): verano / invierno. Los partidos fueron jugados en campo propio contra un equipo visitante diferente. Para garantizar la mayor equivalencia posible en los resultados de los análisis, hemos incluido el mismo número de resultados con el mismo signo (victoria, empate, derrota) para cada uno de los dos equipos: 15 victorias, 2 empates y 1 derrota.

Las crónicas analizadas corresponden a los siguientes partidos:

\begin{tabular}{|c|c|c|c|}
\hline Fecha & Resultado & Fecha & Resultado \\
\hline 2009.09.26 & $\begin{array}{l}\text { R. Madrid - Tenerife: } \\
\text { 3-0 }\end{array}$ & 2010.02.21 & $\begin{array}{l}\text { R. Madrid - Villarreal: } \\
6-2\end{array}$ \\
\hline 2010.10 .23 & R. Madrid - Racing: 6-1 & 2011.03.12 & $\begin{array}{l}\text { R. Madrid - Hércules: } \\
2-0\end{array}$ \\
\hline 2011.11.06 & $\begin{array}{l}\text { R. Madrid - Osasuna: } \\
\text { 7-1 }\end{array}$ & 2012.05.13 & $\begin{array}{l}\text { R. Madrid - Mallorca: } \\
4-1\end{array}$ \\
\hline 2012.12.16 & $\begin{array}{l}\text { R. Madrid - Espanyol: } \\
\text { 2-2 }\end{array}$ & 2013.04.20 & R. Madrid - Betis: 3-1 \\
\hline 2013.09.22 & R. Madrid - Getafe: 4-1 & 2014.05.04 & $\begin{array}{l}\text { R. Madrid - Valencia: } \\
2-2\end{array}$ \\
\hline
\end{tabular}




\begin{tabular}{|l|c|c|c|}
\hline 2014.09.13 & $\begin{array}{c}\text { R. Madrid - At. Madrid: } \\
1-2\end{array}$ & 2015.03 .15 & $\begin{array}{c}\text { R. Madrid - Levante: } \\
\text { 2-0 }\end{array}$ \\
\hline 2015.12.20 & R. Madrid - Rayo: 10-2 & 2016.02 .13 & $\begin{array}{c}\text { R. Madrid - Ath. Bilbao: } \\
\text { 4-2 }\end{array}$ \\
\hline 2016.11 .26 & $\begin{array}{c}\text { R. Madrid - Sporting: } \\
\text { 2-1 }\end{array}$ & 2017.01 .29 & $\begin{array}{c}\text { R. Madrid - R. Socie- } \\
\text { dad: 3-0 }\end{array}$ \\
\hline 2017.11.25 & R. Madrid - Málaga: 3-2 & 2018.02 .24 & R. Madrid - Alavés: 4-0 \\
\hline
\end{tabular}

\begin{tabular}{|c|c|c|c|}
\hline Fecha & Resultado & Fecha & Resultado \\
\hline 2009.09.20 & $\begin{array}{c}\text { Barcelona - At. Madrid: } \\
5-2\end{array}$ & 2010.02 .20 & Barcelona - Racing: 4-0 \\
\hline 2010.11.14 & $\begin{array}{c}\text { Barcelona - Villarreal: } \\
3-1\end{array}$ & 2011.03.05 & $\begin{array}{c}\text { Barcelona - Zaragoza: } \\
\text { 1-0 }\end{array}$ \\
\hline 2011.12.03 & Barcelona - Levante: 5-0 & 2012.05.05 & $\begin{array}{l}\text { Barcelona - Espanyol: } \\
4-0\end{array}$ \\
\hline 2012.12.01 & $\begin{array}{l}\text { Barcelona - Ath. Bilbao: } \\
\text { 5-1 }\end{array}$ & 2013.04 .06 & $\begin{array}{l}\text { Barcelona - Mallorca: } \\
\text { 5-0 }\end{array}$ \\
\hline 2013.09 .14 & Barcelona - Sevilla: 3-2 & 2014.04 .05 & Barcelona - Betis: 3-1 \\
\hline 2014.09.27 & $\begin{array}{l}\text { Barcelona - Granada: } \\
\text { 6-0 }\end{array}$ & 2015.03 .08 & Barcelona - Rayo: 6-1 \\
\hline 2015.12.12 & $\begin{array}{c}\text { Barcelona - Deportivo: } \\
2-2\end{array}$ & 2016.03.12 & Barcelona - Getafe: 6-0 \\
\hline 2016.09.10 & Barcelona - Alavés: 1-2 & 2017.01.14 & $\begin{array}{c}\text { Barcelona - Las Palmas: } \\
\text { 5-0 }\end{array}$ \\
\hline 2017.12 .02 & Barcelona - Celta: 2-2 & 2018.02.24 & Barcelona - Girona: 6-1 \\
\hline
\end{tabular}

Para el análisis léxico hemos usado el programa AntConc. Este programa produce listas de frecuencias léxicas sin lematizar y analiza concordancias de palabras concretas en el corpus textual. Hemos examinado solo las palabras con significado léxico autónomo, que pueden constituir núcleo del sintagma: sustantivos, adjetivos, verbos y adverbios. 


\section{Datos cuantitativos del léxico de las crónicas deportivas analizadas}

Cuantitativamente las listas de palabras se pueden agrupar en palabras gráficas (word tokens) -total de palabras separadas en el texto por espacios- y tipos léxicos (word types) -palabras formalmente diferentes. El análisis cuantitativo de los dos subcorpus (uno de crónicas sobre el Real Madrid y otro sobre el FC Barcelona) da los siguientes resultados:

\begin{tabular}{|c|c|c|c|c|}
\hline \multirow{2}{*}{ Equipos } & \multicolumn{2}{|c|}{ Total palabras } & \multicolumn{2}{c|}{$\begin{array}{c}\text { Palabras con significado } \\
\text { léxico autónomo }\end{array}$} \\
\cline { 2 - 5 } & $\begin{array}{c}\text { Palabras } \\
\text { gráficas }\end{array}$ & Tipos léxicos & $\begin{array}{c}\text { Palabras } \\
\text { gráficas }\end{array}$ & Tipos léxicos \\
\hline Real Madrid & 12255 & 2866 & 5791 & 2655 \\
\hline FC Barcelona & 10992 & 2537 & 5271 & 2345 \\
\hline
\end{tabular}

Dado que se analiza el mismo número de crónicas para ambos clubes (18), destaca el hecho de que el volumen de palabras totales en las crónicas del Real Madrid supere en 1263 palabras (+11,49 \%) a las dedicadas al FC Barcelona, lo que arroja una media de 680,83 palabras para el Real Madrid por 610,67 palabras para el FC Barcelona. Este dato, coincidente con los resultados de Herrero Gutiérrez (2018: 1363), constata que el diario Marca, con sede en Madrid, en su información presta mayor atención al Real Madrid.

\section{La expresión léxica de la identidad del equipo de fútbol}

A continuación analizamos el conjunto léxico que expresa el concepto de ‘equipo’ -también en su faceta de ‘club’ o ‘institución’ deportiva’-. A estos conceptos se asocia la imagen e identidad de un club de fútbol.

Antoni Nomdedeu Rull (2004: 741) define equipo como el "conjunto de jugadores que compite en defensa de una misma entidad”. Este término se refiere al conjunto de los once jugadores en el campo, a los jugadores suplentes del banquillo, y, en un sentido más amplio, 
al club de fútbol como institución. El nombre propio del equipo y los atributos que se le asocian sirven como elemento básico de identidad.

Por su parte, Vivas Holgado (1999: 255) indica que las expresiones léxicas representadas por los archilexemas equipo, club se caracterizan por su ambigüedad designadora, ya que pueden referirse indistintamente al 'grupo total de jugadores de una entidad', y a la 'entidad' misma. Así, “el contenido archilexemático ‘entidad deportiva’ engloba de manera hiperonímica los referentes colectivos 'la directiva', 'la afición', ‘el equipo’ y ‘el cuadro técnico’ para constituir una unidad, que se manifiesta en la esfera léxica del fútbol bajo la forma de recubrimiento de la lengua común entidad" (ibidem: 381). Por lo tanto, desde el punto de vista de la comunidad discursiva de los lectores de la prensa deportiva, con frecuencia "la representación semántica en el plano de la realización -el sintagmático- del referente 'entidad deportiva' descansa solo en una de las colectividades, la del equipo” ( $i b i$ dem). Ello justifica el análisis conjunto de los términos equipo y club. Las denominaciones de los equipos Real Madrid y FC Barcelona que aparecen en el corpus son:

\begin{tabular}{|l|c|c|}
\hline & Denominaciones primarias & Denominaciones secundarias \\
\hline $\begin{array}{l}\text { Real } \\
\text { Madrid }\end{array}$ & $\begin{array}{c}\text { det. + Madrid (111), Real } \\
\text { Madrid (26), R. Madrid (12): } \\
149\end{array}$ & $\begin{array}{c}\text { equipo (44), conjunto (1), } \\
\text { blanco/s (47), merengue/s (10), } \\
\text { madridista/s (13): } 115\end{array}$ \\
\hline $\begin{array}{l}\text { FC } \\
\text { Barcelona }\end{array}$ & $\begin{array}{c}\text { equipo (16), conjunto (2), } \\
\text { lona (21), Barça (58): } 119\end{array}$ & $\begin{array}{c}\text { azulgrana/s (18), culé/s (29), } \\
\text { barcelonista (4), catalanes (4): } \\
73\end{array}$ \\
\hline
\end{tabular}

En consonancia con la mayor extensión de las crónicas del Real Madrid (70 palabras más de media), hay un 25,21 \% más de denominaciones primarias del Real Madrid (149) que del FC Barcelona (119), y hasta un 67,14 \% más de denominaciones secundarias (117 vs. 70). Ello indica una clara tendencia en el diario Marca a subrayar en las crónicas la identidad del Real Madrid, en comparación con lo que ocurre en las crónicas que dedica al FC Barcelona. 
Hemos clasificado las denominaciones en dos tipos:

- Denominaciones primarias, que se refieren al nombre oficial del equipo, y significan la entidad, la institución y el club, y por la elipsis $<$ el equipo de $>+$ el (Real) Madrid y <el equipo de $>+$ el Barcelona, evidencian una clara relación entre el equipo de fútbol y la ciudad. Se incluye la designación Barça, nombre popular en catalán de este club de fútbol. Las denominaciones primarias utilizan el mecanismo de designación por identificación, dado que se fundamentan en el nombre oficial del equipo / club. Pueden aparecer connotadas por el contexto.

- Denominaciones secundarias, que utilizan procedimientos de metonimia y metáfora en relación a los colores del equipo, denominaciones connotadas del término general equipo y denominaciones populares del nivel coloquial. Se incluyen, además, términos derivados del nombre del club (madridista, barcelonista), que funcionan como sustantivos o adjetivos para identificar al equipo o a la institución, o a personas que se identifican con este (jugadores, aficionados). Las denominaciones secundarias utilizan vocablos de empleo normal en el lenguaje deportivo (equipo, conjunto, club...) con significado denotativo o identificativo, que en el transcurso de la crónica deportiva pueden aparecer connotadas por desplazamientos léxico-semánticos y por valoraciones afectivas.

\subsection{Las denominaciones primarias}

La designación identificadora tanto de 'equipo' como de 'club' se sirve de las mismas unidades léxicas, ya que a menudo el equipo representa al club (Vivas Holgado, 1999: 414). El punto de partida de la designación por identificación es el nombre técnico identificador del club de fútbol, que funciona como nombre propio oficial, etiqueta primaria que distingue tanto la identidad afirmativa del equipo y de la entidad como su diferencia frente a los rivales.

Real Madrid y Fútbol Club Barcelona son las etiquetas que cumplen esta función identificadora. No obstante, mientras que el nombre oficial Real Madrid (26) y su versión abreviada R. Madrid (12) aparecen con asiduidad en el corpus, sea en el marcador con el resultado que acompaña a la crónica futbolística, sea en el texto de la crónica 
misma, la forma plena del nombre oficial del club catalán o su forma abreviada FC Barcelona no aparecen nunca. En su lugar, el nombre oficial es sustituido en los marcadores por su acortamiento, Fútbol Club Barcelona = Barcelona (21). Ello produce, ya en el marcador, la identificación del FC Barcelona con la ciudad a la que representa.

Cabe apuntar, además, que en el cuerpo de las crónicas del FC Barcelona, cuando se menciona la ciudad, hay una clara identificación con el equipo, lo que no ocurre en el caso del Real Madrid:

a) Cabía la posibilidad de que los rojiblancos utilizasen la visita a Barcelona como punto de inflexión. Nada más lejos de la realidad. El Atlético se va del Camp Nou totalmente hundido y habiendo encajado nueve goles en tres partidos. Por su parte el Barcelona sale reforzado... (20.09.09)

b) Los goles de Suárez, en dos ocasiones, Messi, Arda Turan y hasta Aleix Vidal devolvieron la tranquilidad a Can Barça, que ya no recordaba lo que era visitar Barcelona (14.01.17).

En el primer caso, es el equipo rival el que visita la ciudad, que metonímicamente se refiere al estadio, e implícitamente al equipo; en el segundo ejemplo, son los aficionados (Can Barça), los que visitan ¡Barcelona!, refiriéndose así al campo de fútbol, y en una referencia más que probable a los muchos aficionados barcelonistas de fuera de Barcelona que se desplazan a la ciudad para asistir al partido de fútbol de su equipo.

Entre las variantes de las denominaciones primarias (aquellas formadas directamente a partir del nombre oficial del equipo), se hallan las formas Madrid (111), Real Madrid (20), y Barcelona (40), Barça (58), precedidas de un determinante ( $\mathrm{el}$, un, este), o de las contracciones al, del. Se trata de designaciones identificadoras formadas por elipsis en un grupo sintagmático con la siguiente estructura: $<$ Elem. Nuclear (contenido genérico 'grupo total de jugadores') + Elem. Adyacente (Nombre propio de la 'entidad' en función identificadora)> (Vivas Holgado, 1999: 283). Como resultado de la elipsis se obtiene la correspondiente denominación, p. ej., el equipo del Real Madrid $\rightarrow$ el Real Madrid. 
El sintagma resultante puede sufrir una nueva elipsis, del adjetivo antepuesto al nombre de la ciudad, dando lugar a la forma el Madrid, coincidente estructuralmente con la forma el Barcelona, obteniéndose así una designación identificadora mediante la actualización de la toponimia de la ciudad (Vivas Holgado, 1999: 284). Un proceso similar de elipsis previa en la designación identificadora se da en el Barça, hipocorístico de Barcelona.

...el Real Madrid venció al Betis con Benzema y Özil... (20.04.13)

Cristiano lideró la victoria del Madrid ante el Getafe... (22.09.13)

EI Barcelona acrecienta la crisis del Atlético con una lección de fútbol (20.09.09).

EI Barça jugó bien en la primera parte... (20.02.10)

\subsection{Las denominaciones secundarias}

Las denominaciones secundarias utilizan sustantivos o adjetivos asociados al nombre propio del equipo. El término equipo está implícito de modo elíptico en las denominaciones el (Real) Madrid, el Barcelona/Barça, a partir del núcleo con adyacente preposicional el equipo del... Una vez que en la crónica futbolística es conocido de qué equipo se habla, como procedimiento de cohesión textual se identifica al equipo de fútbol mediante el uso del término genérico equipo o su sinónimo conjunto, connotado mediante estructuras sintácticas. Ello ocurre en 44 ocasiones para el Real Madrid y 16 para el FC Barcelona.

El Bernabéu silbó al equipo al inicio y se mostró frío según caían los goles... (20.12.15)

Luis Enrique devolvió a Xavi los galones del equipo por primera vez esta temporada (27.09.14).

Las denominaciones equipo y conjunto aparecen en estructuras tales como:

- Núcleo + Adyacente preposicional con el nombre o apellido del entrenador.

...el equipo de Zidane se reveló impotente, desquiciado (25.11.17). 
...el conjunto de Tito volvió a escribir una página en la historia con letra dorada... (01.12.12)

- Núcleo + Proposición subordinada adjetiva especificativa.

...un equipo que terminó haciendo lo que quiso sobre el campo y mostró que su único techo puede ser el cielo $(01.12 .12) \rightarrow$ FC Barcelona.

- Núcleo + Adyacente adjetivo ('color del equipo’)

Ganó el equipo blanco con muchos apuros ante el Málaga.... (25.11.2017)

Así encontró el equipo azulgrana un dominio lento pero seguro, justo pero efectivo (14.01.17).

La primera estructura ejemplificada, la que toma como base identificadora el 'nombre del entrenador del equipo' constituye una designación transitoria por el periodo de tiempo durante el cual se ostenta el cargo de entrenador del equipo en cuestión. Una estructura alternativa que relaciona equipo y entrenador es la estructura elíptica los $d e+<$ nombre del entrenador $>$, donde el elemento elidido es el plural jugadores:

Los de Guardiola golean (4-0) en un partido plácido (20.02.10).

Se trata de estructuras tanto denotativas como connotativas, que subrayan el rasgo específico del autor del estilo de juego del equipo, marcado por el entrenador de turno:

El Bernabéu sigue enamorado de su Madrid de Zidane... (13.02.16)

La alusión al color del equipo es otra designación usada con mucha frecuencia en el lenguaje deportivo, que utiliza el color del uniforme como símbolo de identificación del equipo. Así, "el color en su expresión denotativa se proyecta como elemento identificador mediante una asociación por metonimia” (Vivas Holgado, 1999: 288). Mediante la sinécdoque se sustituye el nombre del equipo por el adjetivo que describe sus colores: blanco/s (47), azulgrana/s (18). Este adjetivo aparece también sustantivado con valor de antonomasia por la relevancia 
deportiva de R. Madrid y FC Barcelona y su uso redundante en la prensa deportiva:

Los blancos, sin pisar el acelerador, ganaron a un buen Betis... (20.04.13). Doblete del luso en el triunfo blanco ante el Getafe (4-1) (22.09.13).

...los azulgranas comenzaron a mover el balón como sólo ellos saben... (01.12.12).

El Camp Nou disfrutó con el juego azulgrana, que no ofrece fisuras (12.03.16).

Para el Real Madrid, se usa connotativamente la metáfora merengue (10), que alude a la similitud con el color blanco de este postre, muy típico de las confiterías madrileñas:

...El festival merengue llegó en el segundo tiempo (21.02.10).

En cuanto al FC Barcelona, destaca el frecuente uso de la designación coloquial del catalán culé/s (33), con el significado de 'perteneciente o relativo al Fútbol Club Barcelona' o ‘jugador o seguidor del Fútbol Club Barcelona':

Exhibición culé en el partido del regreso de Eric Abidal y Tito Vilanova (06.04.13).

Se marcha el mejor entrenador de la historia del Barça pero se queda el mejor jugador, para consuelo de los culés (05.05.12).

Se trata de una designación metafórica, tomada del catalán, que se refiere originariamente a los traseros de los aficionados barcelonistas que sobresalían de los muros del campo, ubicado en la calle Industria, donde jugaba el FC Barcelona entre 1909 y 1922:

La primera imagen que veían los viandantes cuando paseaban por las inmediaciones del campo era la de las posaderas de los aficionados sentados sobre el muro, por lo que a partir de ese momento a los seguidores azulgranas se les empezó a conocer en catalán como “culers”, es decir, los que enseñan el “cul” (culo). La pronunciación de ‘culers' es ‘culés', ese seudónimo que ha perdurado hasta la actualidad (LFP, 2016). 
Finalmente, dentro de los usos connotados, consignamos dos denominaciones que identifican de forma metafórica y coloquial a ambos clubes con sendas casas. Estas son:

Casa Blanca: Es una expresión fija que significa 'el club o la institución del Real Madrid'. Hace referencia al poder institucional y económico del Real Madrid, evocando la imagen de la presidencia norteamericana.

Pero en la Casa Blanca la llama sigue encendida [...] El Real Madrid sigue creyendo en la Liga (13.02.16).

Can Barça: Es el término equivalente para el FC Barcelona, con más arraigo en la cultura catalana. Incluye el término catalán can, palabra usada con frecuencia en catalán para decir la casa de alguien. Así Can Barça (4) significa la casa, la familia, la institución del Barça:

...muestras del mejor fútbol que se puede recordar en 'Can Barça' (01.12.12).

...lo aprovechó Bergantiños para igualar el choque con un gran disparo ante Bravo y poner las dudas en Can Barça (12.12.15).

Especial significación tiene la lengua catalana en la identidad del FC Barcelona, cuyo lema en catalán dice que es mes que un club. La identificación con el entorno humano más cercano se da en el caso del FC Barcelona mediante el uso de la lengua catalana en las denominaciones Barça, culé, Can Barça. Precisamente el gentilicio los catalanes (4) es usado frecuentemente como designación identificadora, hecho que, sin embargo, no se da con el Real Madrid con el gentilicio madrileños, el cual no es usado.

Los catalanes pasaron por encima del colista con los jugadores menos habituales... (06.04.13)

Finalmente, consignamos las designaciones madridista (13) y barcelonista (4), que, referidas originalmente a los aficionados de cada club, se aplican por extensión a todo lo que pertenece o está relacionado con el club, incluido el equipo mismo. El sentimiento de amor y pertenencia a unos colores y a un equipo conlleva una relación exclusiva y excluyente, que identifica a una persona con un club, y que al mismo tiempo lo hace rival de su competidor. En el corpus analizado, estos 
términos no solo se aplican a los aficionados, sino también a los jugadores y al equipo mismo:

El Tenerife siguió a lo suyo y aceptó el pulso madridista (26.09.09).

Nacho cometió penalti [...] Y Cop cogió el balón. Protestaban los madridistas (26.11.16).

El regalo lo agradeció Iniesta, que marcó [...] su primer gol como barcelonista (20.02.10).

\subsection{Valores connotativos de las denominaciones identificativas}

Las expresiones que designan e identifican a los equipos se asocian a una gran variedad de imágenes y usos idiomáticos, que subjetivizan la información referencial que aportan las crónicas. El significado de las expresiones léxicas se ve afectado por connotación de campo semántico diferente o por connotación valorativo-afectiva del referente, apareciendo tanto los términos léxicos ya comentados como nuevos significantes que los sustituyen. A continuación se lista el abanico de connotaciones semánticas que se asocian en el contexto de las crónicas deportivas a uno y otro club de manera repetida.

\section{- Connotaciones semánticas asociadas al Real Madrid:}

a) Violencia, golpes: boxeo, martillo.

Poco o nada tardó el Madrid en soltar un gancho que impactó de lleno en el Tenerife (26.09.09).

...un Real Madrid que es un martillo pilón (26.09.09).

b) Violencia, destrucción.

El Real Madrid aplastó a Osasuna... (06.11.11)

...el Madrid destrozó a un Mallorca que sólo creyó durante un minuto (13.05.12).

c) Poder, inmisericordia.

El Madrid no tuvo piedad de un buen Tenerife y sigue ganando... (26.09.09) 
d) Ejército, guerra.

El juicio a Pellegrini acabó en paseo militar merengue... (21.02.10)

Hubo más damnificados en las filas blancas (04.05.14).

Juicio no existía mucho en la tropa de Zidane, que había decidido apostar por el toque de corneta... (24.02.18)

e) Superioridad, victoria.

...el Real Madrid ganó con la gorra... (12.03.11)

El Madrid ganó como siempre. Con una superioridad insultante (26.11.16).

f) Perfección, excelencia.

El Real Madrid compendió en el último partido todas las virtudes que le han coronado como el mejor campeón de Liga de la historia (23.10.10).

g) Arte musical, espectáculo.

EI cuarteto ofensivo diseñado por Mourinho lleva ya unas cuantas sinfonías y no hay instrumento que desentone en la remozada orquesta merengue (13.05.12).

Pero los blancos no necesitaron mostrar lo mejor de su repertorio... (22.09.13)

Sonó en el Bernabéu la cara A del disco del Madrid de Zidane, la que baila el madridismo... (13.02.16)

- Connotaciones semánticas asociadas al FC Barcelona:

a) Violencia, destrucción.

Los de Guardiola arrollaron a los rojiblancos con su habitual juego... (20.09.09)

Los catalanes pasaron por encima del colista con los jugadores menos habituales... (06.04.13)

b) Poder, inmisericordia.

El Barcelona no tuvo piedad de un Atlético de Madrid de capa caída... (20.09.09)

El Barça hace lo que quiere con el Racing (20.02.10). 
c) Superioridad, victoria.

Es imposible resistir al Barcelona si Leo está enchufado (12.03.16).

d) Perfección, excelencia.

...los azulgrana comenzaron a mover el balón como sólo ellos saben. (01.12.12).

e) Celebración, fiesta.

El Barcelona se dio un festín justo después de sufrir su primera derrota en la Liga (20.02.10).

...Suárez cerró la fiesta azulgrana en el tiempo de prolongación (08.03.15).

...el Barça decidió pegarse un homenaje a costa de Las Palmas... (14.01.17)

f) Arte, espectáculo.

...el espectáculo de los culés acababa de empezar y sus aficionados disfrutaron como en las mejores noches de la era Guardiola... (01.12.12)

g) Leyenda, historia.

El Barça reescribe el inicio de la historia (13.05.12).

h) Fortuna, apoyo sobrenatural.

El Barça sobrevive a una ruleta rusa (14.09.13).

Al Barça se le aparece San Jordi (05.04.14).

\section{La presencia del eterno rival}

Dado que analizamos las designaciones que identifican al Real Madrid y FC Barcelona en partidos donde jugaban contra rivales diferentes, es preciso comentar la sorprendente frecuencia de los tipos léxicos que designan a estos clubes en crónicas de partidos en los que estos no juegan. Así, se cuentan numerosas menciones al máximo equipo rival, esto es, al Real Madrid en crónicas sobre el FC Barcelona, y viceversa. 


\section{- Crónicas del Real Madrid: Barcelona (10), Barça (4):}

En el segundo [tiempo] sesteó, un lujo que, seguramente, no podrá permitirse dentro de siete días en Barcelona (15.03.15).

$Y$ el Levante y el Barça sólo tienen en común los colores de la zamarra (15.03.15).

No parece un buen sintoma antes de viajar a Barcelona (15.03.15).

...le dieron la victoria a los blancos, que se ponen a un punto (engañoso) del Barcelona (13.02.16).

El Madrid se elevó muy por encima de un buen equipo como el Alavés,

[...] que tantos problemas dio al Barça en el Camp Nou (24.02.18).

En los ejemplos anteriores se alude a la mayor dificultad que supondrá enfrentarse al FC Barcelona, a la similitud de los colores del Levante (equipo protagonista de la crónica) con los del Barcelona, a las malas sensaciones en el juego madridista antes de enfrentarse al equipo catalán, $\mathrm{y}$, finalmente, al rendimiento muy superior del Madrid frente a un equipo con el que el Barcelona sufrió muchas dificultades. Como se ve, hay una frecuente comparación con el rival barcelonista (ausente) en estas crónicas del Real Madrid.

\section{- Crónicas del FC Barcelona: Madrid (11):}

... el Barcelona vuelve a pensar en el Arsenal con la ventaja sobre el Madrid intacta (05.03.11).

El Barça está preparado para el Bernabéu (03.12.11).

El Barça asalta el liderato y Messi iguala a Cristiano en la lucha por el pichichi (08.03.15).

...Barcelona, que ha aprovechado de maravilla el bajón futbolístico y competitivo del Madrid (08.03.15).

En estos ejemplos se hace referencia a la distancia en la tabla clasificatoria con respecto al Real Madrid, al buen estado de forma del FC Barcelona antes de la disputa de el clásico que enfrenta a ambos equipos, a la rivalidad paralela entre los dos equipos y sus máximas figuras, y al aprovechamiento del mal momento futbolístico del Real Madrid en beneficio del equipo catalán. 


\section{Conclusiones}

En este estudio ponemos el foco en el género de análisis y opinión más característico de la prensa deportiva, la crónica futbolística. Tomando como base la versión digital del periódico deportivo más leído en España, Marca, hemos seleccionado dos subcorpus equivalentes de partidos disputados por el Real Madrid y el FC Barcelona en su propio estadio en el periodo 2009-2018. El objetivo era analizar cómo se expresa léxicamente la identidad de estos dos equipos, y qué significados connotativos se añaden al léxico identificativo de ambos clubes. Dado que Real Madrid y FC Barcelona son los dos máximos rivales de fútbol español, en segundo lugar nos proponíamos contrastar la identidad de ambos clubes a través de su léxico identificador, e indagar en las crónicas analizadas, en última instancia, si su identidad se apoya también en su rivalidad.

Ayudados del programa AntConc, hemos analizado los tipos léxicos que expresan el concepto 'equipo', mediante el que se identifica a ambos clubes de fútbol. Hemos distinguido dos tipos de denominaciones: primarias y secundarias. Las primarias, de estricto valor identificativo, se basan en el lexema de los nombres oficiales de los equipos, identificados con sus respectivas ciudades (Madrid, Real Madrid, Barcelona, Barça...). Las secundarias son un grupo más heterogéneo formado por vocablos con valor general denotativo, con el archilexema equipo, modificados con adyacentes especificativos preposicionales, adjetivales, oracionales, que adquieren valor identificativo al expresar su relación directa con la toponimia, un entrenador, un estilo de juego, o los colores del uniforme. Igualmente entran en este segundo grupo adjetivos que especifican rasgos caracterizadores de estos equipos (colores, procedencia, afición...) que se nominalizan por metonimia, identificando igualmente a estos clubes (blancos, azulgranas, catalanes, madridistas, barcelonistas). Estas características también son expresadas por medio del lenguaje figurado (merengue, Casa Blanca, Can Barça) y de términos coloquiales (culé).

Unas y otras denominaciones son connotadas en las crónicas con diferentes rasgos y una amplia gama de atributos e imágenes. Así, el 
Real Madrid es un club caracterizado por su indumentaria blanca, que recuerda al pastel de merengue (blanco y agradable), y que muestra su poder, similar al que emana de la Casa Blanca. Su dominio deportivo se basa en la "pegada” pugilística de sus delanteros, que aplasta a la mayoría de sus rivales. El Real Madrid se muestra como un poderoso ‘ejército' dirigido por su entrenador, que obtiene la 'victoria' con una ‘superioridad’ avasalladora, merced a la ‘excelencia’ de su juego, de una calidad comparable a la mejor música.

Enfrente se halla el FC Barcelona. Este es un club con una identidad más apegada a la tierra, a la ciudad. En el mismo marcador el nombre se acorta hasta coincidir con el de la ciudad: Barcelona. Visitar Barcelona significa visitar el campo del FC Barcelona, y viceversa. Allí se habla catalán, el himno se canta en catalán, los jugadores son llamados catalanes, los que pertenecen al club -y el equipo mismose denominan en catalán culés, se grita el nombre del club en catalán -Barça-, la institución también se denomina en catalán Can Barça, en definitiva el FC Barcelona es mes que un club por su identificación con la ciudad y lo catalán. Las connotaciones semánticas habidas en el contexto de las crónicas analizadas muestran a un club dominador, todopoderoso, líder, cuyo juego es motivo de fiesta y disfrute por sus características artísticas, históricas y mágicas.

Al final del análisis llamamos la atención acerca de que la rivalidad entre Real Madrid y FC Barcelona hace que estos equipos sean mencionados en las crónicas deportivas del equipo rival, aun cuando uno de ellos no juegue en ese partido. Ello muestra que el periodista y sus lectores no solo se ocupan de informar y evaluar en la crónica al equipo que juega -Real Madrid o FC Barcelona-, sino que, además, su desempeño se mide en comparación con lo realizado por el máximo rival en otro partido diferente al comentado en la crónica.

\section{Bibliografía}

ÁLVAREZ PEDROSA, F. (2017), La crónica en el diario Marca antes y después de Internet. Análisis de la cobertura de la selección española 
de fútbol (1984-2008), Tesis doctoral, Universidad CEU Cardenal Herrera, Valencia, [on-line] https://repositorioinstitucional.ceu.es/handle/10637/8732, 18.04.2019.

AUGÉ, M. (1999), “¿Un deporte o un ritual?”, en: Segurola, S. (ed.), Fútbol y pasiones políticas, Editorial Debate, Madrid, pp. 55-66.

BROMBERGER, C. (1999), “El revelador de todas las pasiones”, en: Segurola, S. (ed.), Fútbol y pasiones políticas, Editorial Debate, Madrid, pp. 27-36.

HERRERO GUTIÉRREZ, F. J. (2018), “Los periódicos deportivos españoles. Análisis comparativo de la noticia principal de portada en los diarios Marca, As, Mundo Deportivo y Sport”, Estudios sobre el Mensaje Periodístico, 24 (2), pp. 1353-1365, https://doi.org/10.5209/ESMP.62221.

LFP, Liga de Fútbol Profesional (2016), “¿Por qué a los barcelonistas se les llama ‘culés'?”, La Liga (Reportajes, 01.03.2016), [on-line] https:// www.laliga.com/noticias/por-que-a-los-barcelonistas-se-les-llama-cules, 18.04.2019.

MARÍN MONTÍN, J. M. (2000), “La crónica deportiva: José A. Sánchez Araujo”, Ámbitos, 5, pp. 241-257, https://doi.org/10.12795/Ambitos.2001. i05.13.

MARTÍNEZ ALBERTOS, J. L. (1983), Curso General de Redacción Periodística, Mitre, Barcelona.

MEDINA MONTERO, J. F. (2007), “La metáfora en el léxico futbolístico: el caso de los participantes en español, y sus posibles equivalentes en italiano”, en: Luque Toro, L. (ed.), Léxico Español Actual. Actas del I Congreso Internacional de Léxico Español Actual, Ed. Cafoscarina, Venecia-Treviso, pp. 197-239.

MORENO ESPINOSA, P. (2000), "Los géneros periodísticos informativos en la actualidad internacional”, Ámbitos, 5, pp. 169-190.

NARANJO DE ARCOS, A. (2011), Tratamiento de la información deportiva en la prensa: la crónica como género prevalente. El caso de los encuentros de fútbol entre Real Madrid y F.C. Barcelona, Tesis doctoral, Universidad de Málaga, Málaga, [on-line] https://riuma.uma.es/xmlui/ handle/10630/4848, 11.04.2019.

NOMDEDEU RULL, A. (2004), Terminología del fútbol y los diccionarios: elaboración de un diccionario de especialidad para el gran público, 
Tesis doctoral, Universidad Autónoma de Barcelona, Barcelona, [on-line] https://www.tdx.cat/handle/10803/4872, 15.04.2019.

ROJAS TORRIJOS, J. L. (2012), "La futbolización de la información deportiva. Un estudio de casos de cuatro diarios deportivos europeos”, Сотиnicação \& Cultura, 13, pp. 77-95.

ROMERO PÉREZ, B. (2015), “Las crónicas deportivas en la prensa local. El caso de la Unión Deportiva Salamanca en el periódico 'La Gaceta de Salamanca'”, Index, comunicación: Revista científica en el ámbito de la Comunicación Aplicada, 5 (1), pp. 183-212.

VIVAS HOLGADO, J. (1999), El fútbol. Léxico, deporte y periodismo, Ed. de la Universidad de Extremadura, Cáceres.

YANES MESA, R. (2006), “La crónica, un género del periodismo literario equidistante entre la información y la interpretación”, Espéculo, Revista de Estudios Literarios, 32, [on-line] http://www.ucm.es/info/especulo/ numero32/cronica.html, 1.04.2019. 